\title{
The possible significance of parallel changes in plasma lutein and retinol in Pakistani infants during the summer season
}

\author{
BY D. I. THURNHAM ${ }^{1}$, C. A. NORTHROP-CLEWES ${ }^{1}$, P. I. PARACHA ${ }^{2}$ \\ AND U. J. MCLOONE ${ }^{1}$ \\ ${ }^{1}$ Human Nutrition Research Group, School of Biological Sciences, University of Ulster, \\ Coleraine BT52 1SA \\ ${ }^{2}$ Department of Human Nutrition, NWFP Agricultural University, Peshawar, Pakistan
}

(Received 17 April 1996 - Revised 28 April 1997 - Accepted 22 May 1997)

\begin{abstract}
Recent evidence suggests that plasma lutein is better correlated than either $\beta$-carotene or lycopene with its respective carotenoid intake and therefore may be a better marker of vegetable intake than either $\beta$-carotene or lycopene. In the study reported in this paper, measurements of plasma carotenes and retinol were made in infants from two villages near Peshawar in the North West Frontier Province, Pakistan, in July and November 1993. The approximate age at the start was 14 months, and 101 boys and ninety girls completed the study. Of the usual plasma carotenes, only lutein was measurable in all samples and was correlated with retinol in both boys $(r \quad 0.38, P<0 \cdot 0001 ; r 0.35$, $P<0.001)$ and girls $(r 0.21, P=0.038 ; r 0.307, P=0.003)$ at the two time points respectively. In addition, the change in lutein was even more strongly correlated with the change in retinol in both boys $(r 0.453, P<0.0001)$ and girls $(r \quad 0.439, P<0.0001)$. In August $\beta$-carotene was measurable in approximately $8 \%$ of samples and this increased to $31 \%$ in November but there was no correlation between $\beta$-carotene and retinol at any time. There were negligible amounts of lycopene and $\beta$ cryptoxanthin in plasma at both time points. The mean concentration of plasma retinol in the infants was $0.66 \mu \mathrm{mol} / \mathrm{l}$ at baseline and $59 \%$ of the infants had retinol concentrations $<0.7 \mu \mathrm{mol} / \mathrm{l}$. In addition, there were fifteen infants whose levels were below $0.35 \mu \mathrm{mol} / \mathrm{l}$ suggesting that vitamin $A$ status in the population was marginal. Food intake of the infants was not monitored in the present study but breast feeding continues for up to 2 years in this part of Pakistan and most infants would be weaned onto selected foods eaten by the family. The close correlation between plasma lutein and retinol suggests that the increase in retinol over the summer season may be attributable to an increased availability of green vegetables to the families. The source of lutein to the infants is most likely to be the breast milk since such vegetables are unlikely to be given to infants except to suck as a weaning food. The results may indicate the potential usefulness of plasma lutein as a marker of changes in vegetable intake and changes in vitamin $A$ status in Third World infants and children.
\end{abstract}

Lutein: Carotenoids: Vitamin A: Infants

The intakes of lutein, lycopene and $\beta$-carotene were recently measured in a group of Cambridge women and it was found that, of the three carotenes, dietary lutein was the most strongly correlated with its plasma concentration (Scott et al. 1996). It was also observed that mean plasma lutein concentrations in blood from subjects (45-65 years) living in Toulouse (Southern France), where the frequency of consumption of vegetables was twenty times per week, were twice as high (men 0.564 , women $0.615 \mu \mathrm{mol} / \mathrm{l}$ ) as those of similar subjects living in Belfast (men 0.266, women $0.293 \mu \mathrm{mol} / \mathrm{l}$ ) where vegetables were consumed less frequently (Thurnham et al. 1994; Howard et al. 1996). 
Lutein is present in most leafy green vegetables in approximately the same amounts as $\beta$-carotene (Heinonen et al. 1989; Granado et al. 1996) and lycopene is predominantly present in tomato-based products. $\beta$-Carotene is the main dietary carotenoid with provitamin A properties. All three carotenes are absorbed along with dietary fat into mucosal cells where most conversion of pro-vitamin A carotenoids to retinol occurs. Non-provitamin A carotenoids, retinol (as retinol palmitate) and any remaining $\beta$-carotene are then transported to the liver by the chylomicrons. Subsequently, carotenes are redistributed to the rest of the body via the lipoproteins. All carotenes are believed to accompany $\beta$ carotene through the absorption process but may compete with one another in different ways (Zeng et al. 1992; Kostic et al. 1995). However, as far as is known, there is far less metabolism of non-pro-vitamin A carotenoids than pro-vitamin A carotenoids in man, thus it seems more likely that non-pro-vitamin A carotenoids should appear in blood in closer proportion to the amount consumed than the amount of $\beta$-carotene in the dietary intake.

Vegetables and fruits are the most important food sources of vitamin A in developing countries (Olson, 1984). However in Western countries, vegetables and fruits are less important contributors and the correlation between plasma concentrations of the major carotenoids and plasma retinol levels is at best poor and often not detectable. However, the main reason for the lack of a correlation is that plasma retinol concentrations are tightly controlled and independent of dietary intake or vitamin A stores until vitamin A concentrations in the liver fall to low levels (Olson, 1984). Thus, vitamin A supplements do not influence plasma retinol levels in Western populations (Willett et al. 1983) but have been shown to increase plasma retinol in developing countries where circulating retinol levels are usually much lower (Sommer et al. 1986; Thurnham et al. 1988a). In these circumstances plasma retinol would also be expected to correlate better with plasma carotene levels as both plasma retinol and plasma carotenes will be more dependent on the intake of fruit and vegetables (Solomons \& Bulux, 1993). However, the best correlations should be with the non-pro-vitamin A carotenoids since an unknown amount of dietary $\beta$ carotene will be converted to retinol and will never enter the circulation as $\beta$-carotene.

The objective of the present study was to report on observations which appear to link plasma lutein with plasma retinol concentrations in infants in a developing country. Measurements of plasma retinol and carotene concentrations were made on blood samples collected from Pakistani infants before and after a placebo-controlled, double-blind Fesupplementation study. It should be emphasized however, that the work reported here was not planned when the Fe-supplementation study was being organized. However, marginal vitamin A status was suspected in these infants and therefore the opportunity to collaborate with the author (P.I.P.) was used to investigate some of the factors possibly influencing vitamin A status in the samples after completion of the study.

Some of these data were first presented as an abstract and poster at the XVII Meeting of the International Vitamin A Consultative Group in March 1996 and other data from the same study on the interaction of the Fe treatment with vitamin A status have been reported by Northrop-Clewes et al. (1996).

\section{MATERIALS AND METHODS}

\section{Subjects}

Three hundred infants aged less than 2 years were recruited for an Fe-supplementation study from two villages in an area about $20 \mathrm{~km}$ north-east of Peshawar in North West Frontier Province, Pakistan. Ages were confirmed with the help of a local events calendar. Mean age was 14 months in August 1993. The following infants were excluded: those 
receiving supplementary $\mathrm{Fe}$ in one form or another (all medicines being taken were examined), those with a family history or clinical features of thalassaemia (e.g. broad face with high cheek bones, frontal bossing and a mild to moderate enlargement of the spleen), severely malnourished infants (weight for age < 5th percentile of the NCHS standards; National Center for Health Statistics, 1976) and those with obvious clinical symptoms of acute or chronic infections. Ethical approval was obtained from Harvard University, Boston, USA with whom one of the authors (P.I.P.) collaborated for the Fesupplementation study, and informed consent was obtained from each household.

\section{Blood samples}

Pre-supplementation blood was collected in mid-July 1993 from 265 infants who were then randomly allocated to receive either $F e(15 \mathrm{mg})$ or placebo daily for 12 weeks. Postsupplementation blood was taken at the beginning of November from 214 subjects and the final data set contained 191 complete records (group A); that is, there were seventy-four subjects who either failed to complete the study or from whom the blood sample was inadequate for all measurements (group B). Plasma was separated and stored at $-20^{\circ}$ until March 1994 when it was shipped in solid $\mathrm{CO}_{2}$ to Coleraine in Northern Ireland. Samples were analysed randomly for all analytes and analyses were completed by the end of April 1994.

\section{Measurement of plasma carotenes}

Plasma carotenes, retinol and vitamin $\mathrm{E}$ were measured by liquid chromatography in $0.1 \mathrm{ml}$ plasma by the method of Thurnham et al. $(1988 \mathrm{~b})$ which was modified to measure lutein using the $145.1 \mathrm{mmol}$ extinction coefficient. Lutein in this system elutes in a combined peak with zeaxanthin, but in our experience, the amount of zeaxanthin is not more than $10 \%$. Reagents included HPLC-grade ethanol, methanol, dichloromethane, acetonitrile, heptane and hexane (E. Merck, Poole, Dorset). The standards used were retinol, $\alpha$-carotene, $\beta$-carotene, lycopene, tocopherol, tocopheryl acetate (E. Merck), $\beta$ cryptoxanthin and lutein (gifts from F. Hoffmann-La Roche Ltd, Basel, Switzerland).

Briefly, $0.1 \mathrm{ml}$ plasma was mixed with $0.1 \mathrm{ml}$ aqueous $\operatorname{SDS}(10 \mathrm{mmol} / \mathrm{l})$ and $0.2 \mathrm{ml}$ internal standard (tocopheryl acetate $84 \mu \mathrm{mol} / \mathrm{l}(40 \mathrm{mg} / \mathrm{l})$ in ethanol). The micronutrients were extracted into $1.0 \mathrm{ml}$ heptane containing butylated hydroxytoluene (BHT, $0.5 \mathrm{~g} / \mathrm{l}$ ), and $0.7 \mathrm{ml}$ of the supernatant heptane fraction was removed, evaporated under $\mathrm{N}_{2}$ and reconstituted with $0.1 \mathrm{ml}$ mobile phase (acetonitrile-methanol-dichloromethane, $47: 47: 12$ by vol.). The final extract $(50 \mu \mathrm{l})$ was injected automatically onto a $3 \mu \mathrm{m}$ Spherisorb ODS-2 column $(100 \times 4 \mathrm{~mm}$, Phase Separations Ltd, Clwyd), separated at a flow rate of $1.0 \mathrm{ml} / \mathrm{min}$ and the micronutrients detected using two channels of a Waters 470 4-channel detector (Millipore UK Ltd, Watford, Herts.). Minimum detection level varied from $0.005 \mu \mathrm{mol} / 1$ for the carotenoids to $0.01 \mu \mathrm{mol} / 1$ for retinol. The intra-batch $\mathrm{CV}$ of a pooled plasma sample was found to be $5.8 \%$ for retinol (mean value of $0.98 \mu \mathrm{mol} / \mathrm{l}$ ), $6.9 \%$ for lutein $(0.462 \mu \mathrm{mol} / 1), 11.2 \%$ for $\alpha$-carotene $(0.044 \mu \mathrm{mol} / 1)$ and $5.8 \%$ for $\beta$-carotene $(0.357 \mu \mathrm{mol} / 1)$.

\section{Statistical analysis of the data}

With the exception of plasma immunoglobulin (Ig) $G$ values, there were no significant differences in any micronutrient, haematological variable or marker of infection between 
the Fe-treated and placebo groups at baseline (Northrop-Clewes et al. 1996). Therefore, the data were stratified by sex to provide two independent subpopulations for analysis.

Lutein and $\beta$-carotene values were not normally distributed so the data were transformed to logarithms (base-10) values and analysed using parametric statistics. Data are reported as arithmetic means with their standard errors or in the case of lutein and $\beta$ carotene as geometric means with their standard errors. The only exception to this was in the case of the changes in lutein concentrations which were calculated by subtracting baseline values from the follow-up values. These data were not skewed therefore they were not transformed for analysis (Statistical Package for the Social Sciences, SPSS-PC+ version 3.1, SPSS UK Ltd, Chertsey, Surrey).

\section{RESULTS}

In the final sample there were 101 boys and ninety girls. Slightly more boys $(n 52)$ received Fe than girls ( $n 43)$ but a similar numbers of boys $(n 49)$ and girls $(n 47)$ received the placebo. There were no differences in plasma retinol and the carotenoids between the two treatment groups (Northrop-Clewes et al. 1996). There was also little difference between the sexes (Table 1); nevertheless the data analysed here are shown separately by sex to provide two independent samples for the analyses.

The only carotenes present in appreciable amounts in the plasma of the infants were lutein and $\beta$-carotene; that is, lycopene and $\beta$-cryptoxanthin were below detection limits in almost all samples. In addition, in the case of $\beta$-carotene, only $8 \%$ of the results at baseline were above the level of detection (nine boys, four girls) so the number of results was too small to compare groups A and B or between the sexes. Furthermore the increase in concentration of $\beta$-carotene between baseline and follow-up was negligible but the proportion of detectable results did increase from 8 to $31 \%$ (thirty-four boys, twenty-five girls) over the 3 months. There was no correlation between $\beta$-carotene and retinol at either time point or in either sex.

Table 1. Plasma concentrations of lutein, retinol and $\alpha$-tocopherol $(\mu \mathrm{mol} / \mathrm{l})$ in boys and girls enrolled in an iron supplementation study who subsequently either completed the study (group A) or failed to complete the study (group B)*

(Mean $\dagger$ values with their standard errors)

\begin{tabular}{|c|c|c|c|c|c|c|c|c|c|c|c|}
\hline \multirow[b]{4}{*}{ Variable } & \multicolumn{4}{|c|}{ Boys } & \multicolumn{4}{|c|}{ Girls } & & & \\
\hline & \multirow{2}{*}{\multicolumn{2}{|c|}{$\begin{array}{c}\text { Group A } \\
(n \text { 101) }\end{array}$}} & \multirow{2}{*}{\multicolumn{2}{|c|}{$\begin{array}{c}\text { Group B } \\
(n 44)\end{array}$}} & \multirow{2}{*}{\multicolumn{2}{|c|}{$\begin{array}{c}\text { Group A } \\
(n 90)\end{array}$}} & \multirow{2}{*}{\multicolumn{2}{|c|}{$\begin{array}{c}\text { Group B } \\
(n 30)\end{array}$}} & \multicolumn{3}{|c|}{ ANOVA } \\
\hline & & & & & & & & & Resno & & \\
\hline & Mean & $\mathrm{SE}$ & Mean & $\mathrm{SE}$ & Mean & $\mathrm{SE}$ & Mean & $\mathrm{SE}$ & $P=$ & $P=$ & $P=$ \\
\hline$\overline{\text { Lutein }}$ & 0.067 & 0.005 & 0.077 & 0.006 & $0-081$ & 0.005 & 0.070 & 0.009 & 0.845 & 0.152 & 0.102 \\
\hline Retinol & 0.66 & 0.023 & 0.69 & 0.032 & 0.66 & 0.024 & 0.60 & 0.039 & 0.817 & 0.386 & 0.138 \\
\hline$\alpha$-Tocopherol & $7 \cdot 17$ & 0.322 & 8.09 & 0.444 & 8.45 & 0.380 & 7.49 & 0.605 & 0.774 & 0.069 & 0.046 \\
\hline Age (d) & 416 & 5.8 & 415 & $7 \cdot 2$ & 421 & $5 \cdot 9$ & 418 & 8.8 & 0.820 & 0.494 & 0.835 \\
\hline
\end{tabular}

* A total of 265 infants provided a baseline blood sample at the start of the supplementation study. Those completing the study ( $n$ 191, group A) provided another sample 3 months later while the remainder (group B) failed to provide the second sample.

$\dagger$ Values are arithmetic means except for lutein which are geometric means.

$\ddagger$ There were no significant differences between subjects in groups A and B or between the boys and girls $(2 \times 2$ ANOVA by response and sex). 
Table 2. Plasma lutein and retinol concentrations ( $\mu$ mol/l) in boys and girls before (baseline) and after (follow-up) their participation in a double-blind, placebo-controlled iron supplementation study*

(Mean $\dagger$ values with their standard errors)

\begin{tabular}{|c|c|c|c|c|c|c|}
\hline \multirow[b]{2}{*}{ Variable } & \multirow[b]{2}{*}{ Study interval $\ddagger$} & \multicolumn{2}{|c|}{$\begin{array}{c}\text { Boys } \\
(n \text { 101) }\end{array}$} & \multicolumn{2}{|c|}{$\begin{array}{l}\text { Girls } \\
(n 90)\end{array}$} & \multirow{2}{*}{$\begin{array}{c}t \text { test } \\
P=\end{array}$} \\
\hline & & Mean & $\mathrm{SE}$ & Mean & SE & \\
\hline \multirow[t]{3}{*}{ Lutein } & Baseline & 0.067 & 0.005 & 0.081 & 0.005 & 0.047 \\
\hline & Follow-up" & 0.169 & 0.010 & $0 \cdot 170$ & 0.013 & 0.933 \\
\hline & Difference & 0.111 & 0.010 & $0 \cdot 110$ & 0.012 & $0 \cdot 150$ \\
\hline \multirow{3}{*}{ Retinol } & Baseline & 0.66 & 0.024 & 0.66 & 0.024 & 0.971 \\
\hline & Follow-up" & 0.78 & 0.028 & 0.79 & 0.029 & 0.668 \\
\hline & Difference & 0.12 & 0.033 & 0.13 & 0.029 & 0.056 \\
\hline
\end{tabular}

* For details of subjects and procedures, see pp. 776-778.

$\dagger$ Baseline and follow-up values for lutein are geometric means. All other values are arithmetic means.

$\ddagger$ Twelve weeks from the middle of July 1993 to the beginning of November 1993 .

$\S$ Differences between the sexes.

" All post-supplementation results were significantly different from those before supplementation, $P<0.001$ (paired $t$ test).

Table 1 shows a comparison of baseline data for age and the plasma concentrations of lutein, retinol and $\alpha$-tocopherol from those subjects who completed the supplementation study (group $A ; n$ 191), and those subjects for whom only baseline data were obtained (group $\mathrm{B} ; n$ 74). As can be seen, there were no differences in any of the variables shown between the two groups for either sex.

Table 2 shows the mean concentrations of lutein and retinol for the sexes separately at baseline and follow-up and the mean changes in these variables in the two groups. Girls had slightly higher concentrations of lutein than boys at the start $(P=0.047)$ but there were no other differences between the sexes. At follow-up however both lutein and retinol were significantly increased in both sexes $(P<0.001)$.

Table 3. Regression statistics for lutein and retinol at baseline and at follow-up and on the differences in these variables between the two time points

\begin{tabular}{|c|c|c|c|c|c|}
\hline & B-intercept & SE B & Beta & $\mathrm{T}$ & Sigma T \\
\hline \multicolumn{6}{|l|}{ Baseline } \\
\hline Boys: Lutein $(\log 10)$ & 0.289 & 0.070 & 0.382 & $4 \cdot 127$ & 0.0001 \\
\hline Constant & 1.000 & 0.085 & & 11.715 & 0.0000 \\
\hline Girls: Lutein $(\log 10)$ & 0.301 & 0.086 & 0.349 & 3.494 & 0.0007 \\
\hline Constant & 0.990 & 0.097 & & 10.238 & 0.0000 \\
\hline \multicolumn{6}{|l|}{ Follow-up } \\
\hline Boys: Lutein $(\log 10)$ & $0 \cdot 238$ & 0.114 & 0.205 & 2.089 & 0.0393 \\
\hline Constant & 0.959 & 0.092 & & 10.376 & 0.0000 \\
\hline Girls: Lutein $(\log 10)$ & 0.281 & 0.093 & 0.307 & 3.031 & 0.0032 \\
\hline Constant & 1.008 & 0.076 & & 13.197 & 0.0000 \\
\hline \multicolumn{6}{|l|}{ Differences } \\
\hline Boys: Lutein (arithmetic) & 1.596 & $0 \cdot 315$ & 0.453 & $5 \cdot 060$ & 0.0000 \\
\hline Constant & -0.061 & 0.045 & & -1.333 & 0.1855 \\
\hline Girls: Lutein (arithmetic) & 1.086 & 0.237 & 0.439 & 4.577 & 0.0000 \\
\hline Constant & 0.012 & 0.037 & & 0.322 & 0.7485 \\
\hline
\end{tabular}



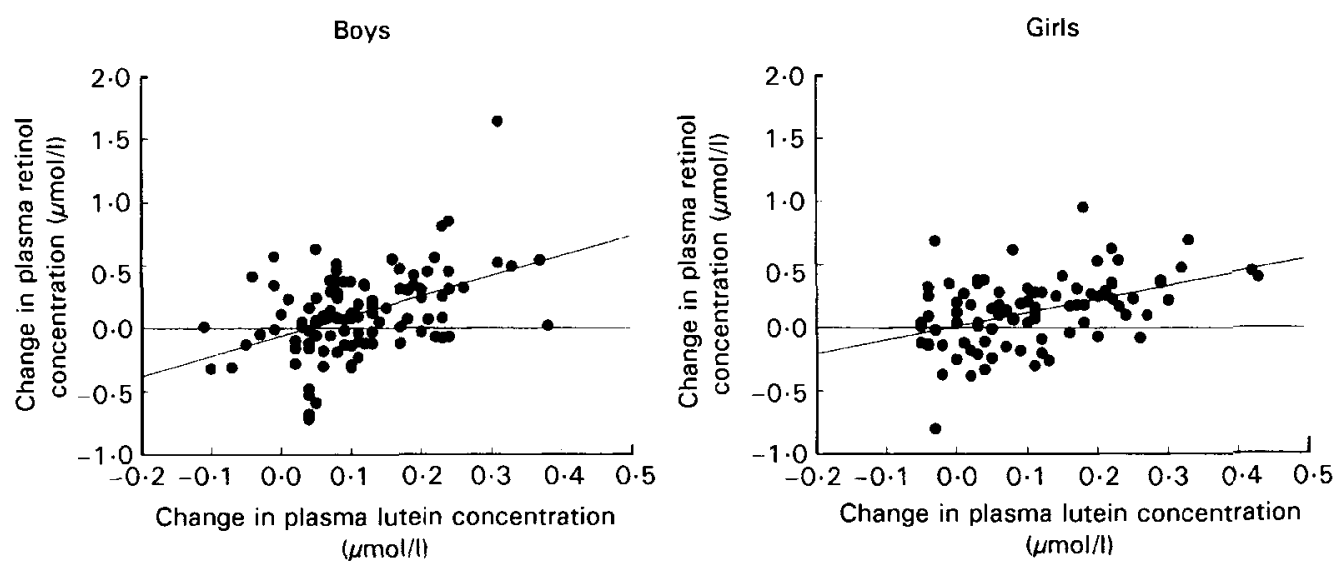

Fig. 1. The relationship between the changes in plasma lutein $(\mu \mathrm{mol} / \mathrm{l})$ and plasma retinol $(\mu \mathrm{mol} / \mathrm{l})$ over a period of approximately $3.5-4$ months in 101 male and ninety female Pakistani infants. In both boys $(r 0.45, P<0.0001)$ and girls $(r 0.44, P<0.0001)$ the increase in plasma lutein was strongly correlated with the increase in retinol. The slopes of the regression lines were 1.594 (boys) and 1.086 (girls).

Table 3 shows the regression statistics for the plasma retinol and lutein. At baseline, lutein (log base-10) correlated with retinol in both boys $(r 0.38, P<0.0001)$ and girls $(r$ $0.35, P<0.001$ ), explaining 14 and $11 \%$ of the variance in retinol respectively. At the end of the study lutein was less strongly correlated with retinol in both sexes (boys $r 0.21$, $P=0.039$; girls $r 0.31, P=0.003$ ) explaining only 3 and $8 \%$ of the variance in plasma retinol respectively. At the two time points, slopes of the regression lines for both boys $(0.289$ and 0.238$)$ and girls $(0.301$ and 0.281$)$ and the intercepts with the ' $y$ ' axis were of a similar magnitude (Table 3 ).

Fig. 1 shows the correlations between the changes in lutein and retinol over the 3.5month period. There was a similar picture in both sexes and the correlations were stronger than those at the individual time points (boys $r 0.45, P<0.0001$; girls $r 0.44, P<0.0001$; Table 3) with lutein explaining 20 and $18 \%$ of the variance of the change in retinol respectively. The slopes of the regression lines were similar for both boys (1.596) and girls $(1.086)$.

\section{DISCUSSION}

As there was no intention in the original study design to examine either vitamin $\mathrm{A}$ or carotenoids status in the infants, no dietary information was collected on either the infants or their mothers during the study. However all infants were breast fed with some supplementary feeding. Typically in this region, exclusive breast feeding continues for 9-10 months before weaning foods are introduced. Commercial weaning foods are rarely used in the villages in North West Frontier Province because of cost and unavailability, and typical weaning foods include bread, wheat porridge, mashed potato and banana, a slice of apple or orange to suck, weak tea with added cows' milk etc. (C. Northrop-Clewes and P. Paracha, unpublished results). Such foods contain very little carotene and, with the exception of the cows' milk, most would be of poor bioavailability. In these circumstances, it would be expected that most of the infants would obtain their dietary vitamin $A$ and carotenoids from breast milk since breast feeding continues for up to 2 years or more. It is possible, therefore, that the increases in lutein and retinol in the infants' plasma samples 
are representative of increased green vegetable intake by the mothers during the study. The study was done at the start of the summer season and increased amounts of fruits and vegetables would have been available to the mothers during the course of the $\mathrm{Fe}$ supplementation study.

It is also possible, however, that sample deterioration may have contributed to the results. The baseline samples were collected in July 1993 and the follow-up samples in November the same year. Samples were stored at $-20^{\circ}$ until March 1994 when they were sent to Coleraine in solid $\mathrm{CO}_{2}$ and were still frozen on arrival. Analyses were complete by the end of April. The baseline samples were therefore stored for approximately 10 months and the follow-up samples for 6 months. We have previously shown that carotenes deteriorate progressively when plasma is stored at $-20^{\circ}$. In control plasma which was analysed routinely over 1 year, mean values for $\beta$-cryptoxanthin, lycopene, $\alpha$ - and $\beta$ carotene fell by $26,21,7$ (NS) and $22 \%$ over 12 months and the fall was significant from 6 months onwards (Thurnham \& Flora, 1988a). We were not measuring lutein at that time but there is no reason to think that it would be any different to these other carotenoids. If a $25 \%$ deterioration in lutein is assumed over 12 months, then the baseline values may have been 0.084 and $1.01 \mu \mathrm{mol} / \mathrm{l}$ in the boys and girls respectively (Table 2). The follow-up samples would also have deteriorated slightly but, if it is assumed that they did not change (worst case situation), the mean differences between the baseline and follow-up are still significant at 0.085 and $0.069 \mu \mathrm{mol} / \mathrm{l}$ in the two groups respectively.

In the case of retinol and $\alpha$-tocopherol, Thurnham \& Flora (1988a) found no evidence of any deterioration in these analytes over 12 months. It is possible that stored samples in Pakistan were not always maintained at $-20^{\circ}$ as the electricity supply is sometimes unreliable. However, as far as we know the samples were thawed once for ferritin analysis and were otherwise undisturbed. In contrast, the samples of Thurnham \& Flora (1988a) were thawed three times and were in a vertical freezer which was frequently opened. In other words we have no reason to suspect that the Pakistani samples were any more severely treated than those of Thurnham \& Flora $(1988 a)$. Therefore the changes in plasma lutein and retinol which were observed in the Pakistani infants would appear to be real.

The mean concentration of plasma retinol in the infants at baseline was $0.66 \mu \mathrm{mol} / \mathrm{l}$ with $59 \%<0.7 \mu \mathrm{mol} / \mathrm{l}$ and $6 \%(n 15)$ of the results $<0.35 \mu \mathrm{mol} / \mathrm{l}$ (eight boys, seven girls). Such concentrations of retinol probably indicate low liver vitamin A stores (Olsen, 1984; Pilch, 1985). The increase in plasma retinol during the study may represent the normal increase with age; however the increase in retinol was correlated with the increase in lutein in both sexes. No age-related increase in plasma carotenoids has been reported in infants. Furthermore, at both the beginning and the end of the study, absolute concentrations of retinol were similarly correlated with the absolute amounts of lutein suggesting that the increase in lutein paralleled the increasing concentrations of retinol. It has recently been reported that plasma lutein correlates more strongly with sources of dietary lutein than either plasma lycopene or $\beta$-carotene (Scott et al. 1996). The strong correlation between retinol and lutein in the infants' blood suggests that a significant proportion of the increases in retinol may have been derived predominantly from green vegetable sources. Furthermore, the absence of any other consistently-appearing carotenoid in the blood of the infants emphasizes the potential importance of lutein as a marker of green vegetable intake.

$\beta$-Carotene was not detectable in most of the samples analysed. Furthermore there was no correlation between $\beta$-carotene concentrations and plasma retinol in those samples with detectable measurements either at the start or end of the study. Since there were only $8 \%$ valid measurements at the start, the results are of little value. However, there were $66 \%$ 
valid cases, i.e. where plasma $\beta$-carotene could be measured, at the end of the study. In these samples, the absence of a correlation between plasma $\beta$-carotene and retinol suggests that $\beta$-carotene did not appear in the blood in proportion to the retinol present. In addition, the continued absence of detectable $\beta$-carotene from the blood of many of the infants, suggests that dietary $\beta$-carotene was converted to retinol either by the mother and/or the infant and very little was therefore available to pass into the infant's blood stream.

A recent study in Indonesian lactating women reported no increase in plasma vitamin A, $\beta$-carotene or lutein following a vegetable supplement (de Pee et al. 1995). It is in circumstances like this where plasma lutein may prove to be a useful marker to quantify the response to the vegetable supplement. The mean concentration of plasma lutein in the women before the supplementation started was $0.48 \mu \mathrm{mol} / \mathrm{l}$. This is many times higher than that in the Pakistani infants and almost double that found in British women (median $0.286 \mu \mathrm{mol} / \mathrm{l}$; Thurnham \& Flora, $1988 \mathrm{~b}$ ). Lutein concentrations of about $0.6 \mu \mathrm{mol} / 1$ were obtained in French women consuming vegetables on average twenty times per week (Howard et al. 1996) thus the lutein concentrations in the Indonesian women indicate that they were already consuming large amounts of vegetables. There is already much evidence to show that carotene may be only poorly bioavailable from vegetable foods (Solomons \& Bulux, 1993). Therefore, it is quite likely that increasing the vegetable intake of women who are already consuming a diet containing a high proportion of vegetables will be poorly effective. Furthermore, vegetable foods are bulky foods, thus even though the extra vegetable was taken at the beginning of the day before any of the main meals the additional bulk of the morning supplement may have suppressed food intake in the rest of the day. The extra vegetable given amounted to the equivalent of $3.5 \mathrm{mg} \beta$-carotene. The mean daily vegetable intake of women in Great Britain provides $2.1 \mathrm{mg} \beta$-carotene (Gregory et al. 1990); thus, the extra vegetable supplement was equivalent to almost twice the average daily intake in Great Britain. If one considers this amount added to an Indonesian diet, which already contains generous amounts of vegetables (indicated by the plasma lutein concentrations), the physical difficulty of consuming the extra vegetables becomes apparent.

The recent study by Kostic et al. (1995) showed that $\beta$-carotene and lutein interact with one another during absorption. $\beta$-Carotene consistently reduced serum levels of lutein by $54-61 \%$ when the two carotenes were administered together. Lutein, on the other hand, was less consistent in its effects on $\beta$-carotene in that in reduced serum levels in five but elevated them in the other three subjects. However, in terms of the response of the individuals to the carotene treatments administered separately, there were broad similarities. There was much heterogeneity between subjects in their response to the carotene treatment, nevertheless subjects who showed the highest response to lutein treatment, tended to show the highest response to $\beta$-carotene (Spearman rank, $P=0.066$ ). Furthermore there was no significant difference in the clearance rates of lutein and $\beta$ carotene from serum $(P<0 \cdot 1)$. Thus although carotenes may interact somewhat inconsistently during absorption, where the amounts of lutein and $\beta$-carotene are similar in the dietary intake, the response within an individual appears to be similar and clearance rates do not differ. Hence although plasma $\beta$-carotene and retinol may not change when subjects in the developing world are supplemented with green leafy vegetables because of concomitant chronic or acute disease or continuing inadequate vitamin A status, lutein values are more likely to increase and indicate that vegetable intake has increased and changes in vitamin A status may well have occurred.

In recent years there have been several reports which have increased our knowledge on lutein composition of vegetable foods in Western countries (Heinonen et al. 1989; Granado 
et al. 1992, 1996; Chug-ahuja et al. 1993; Hart \& Scott, 1995) and more recently from the Indian subcontinent (Bhaskarachary et al. 1996). These have shown lutein to be widely distributed and an important component in green vegetables but also to be present in smaller quantities in some fruits such as mangos and papaya (Bhaskarachary et al. 1996). It seems likely that this widespread distribution of lutein in the plant kingdom accounts for our observation that lutein is the most consistently found component in the plasma carotene profile from human blood.

In conclusion, plasma lutein and retinol concentrations were correlated in both male and female infants at two time points, 3.5 months apart. In addition the changes in lutein concentrations beween the two time points were correlated with the changes in plasma retinol in both sexes. As lutein is predominantly found in green vegetable foods, these data suggest that in those poor socio-economic environments where dietary sources of vitamin $A$ are predominantly of vegetable origin, plasma lutein may be a useful marker of green vegetable intake and possibly also of changes in vitamin A status. A suitable study in which dietary information is collected and information on changes in plasma carotenes is obtained is needed to confirm this.

The Fe-supplementation study was supported jointly by the Applied Diarrheal Disease Research (ADDR) Project at the Harvard Institute for the International Development by means of a cooperative agreement with the United States Agency for International Development (USAID), and by the United Nations Children's Fund (UNICEF), Islamabad, Pakistan.

\section{REFERENCES}

Bhaskarachary, K., Sankara Rao, D. S., Deosthale, Y. G., Rani, M. \& Reddy, V. (1996). Provitamin A carotenoid content of common foods. In XVII International Vitamin A Consultative Group Meeting 7, p. 83. Washington, DC: ILSI Human Nutrition Institute.

Chug-ahuja, J. K., Holden, J. M., Forman, M. R., Mangels, A. R., Beecher, G. R. \& Lanza, E. (1993). The development and application of a carotenoid database for fruits, vegetables, and selected multicomponent foods. Journal of the American Dietetic Association 93, 318-323.

de Pee, S., West, C. E., Muhilal, Karyadi, D. \& Hautvast, J. G. A. J. (1995). Lack of improvement in vitamin A status with increased consumption of dark-green leafy vegetables. Lancet 346, 75-81.

Granado, F., Olmedilla, B., Blanco, I. \& Rojas-Hidalgo, E. (1992). Carotenoid composition of raw and cooked Spanish vegetables. Journal of Agricultural and Food Chemistry 40, 2135-2140.

Granado, F., Olmedilla, B., Blanco, I, \& Rojas-Hidalgo, E. (1996). Major fruit and vegetable contributors to the main serum carotenoids in the Spanish diet. European Journal of Clinical Nutrition 50, 246-251.

Gregory, J. R., Foster, K., Tyler, H. \& Wiseman, M. (1990). The Dietary and Nutritional Survey of British Adults. London: H.M. Stationery Office.

Hart, D. J. \& Scott, K. J. (1995). Development and evaluation of an HPLC method for the analysis of carotenoids in foods, and the measurement of carotenoid content of vegetables and fruits commonly consumed in the UK. Food Chemistry 54, 101-111.

Heinonen, M. I., Ollilainen, V., Linkola, E. K., Varo, P. T. \& Koivistoinen, P. E. (1989). Carotenoids in Finnish foods: vegetables, fruits, and berries. Journal of Agricultural and Food Chemistry 37, 655-659.

Howard, A. N., Williams, N. R., Palmer, C. R., Cambou, J. P., Evans, A. E., Foote, J. W., Marques-Vidal, P., McCrum, E. E., Ruidavets, J. B., Nigdikar, S. V., Rajput-Williams, J. \& Thurnham, D. I. (1996). Do hydroxy carotenoids prevent coronary heart disease? A comparison between Belfast and Toulouse. International Journal of Vitamin and Nutrition Research 66, 113-118.

Kostic, D., White, W. S. \& Olson, J. A. (1995). Intestinal absorption, serum clearance, and interactions between lutein and $\beta$-carotene when administered to human adults in separate or combined doses. American Journal of Clinical Nutrition 62, 604-610.

National Center for Health Statistics (1976). Growth Charts. Rockville, MD: US Department of Health, Education and Welfare, Public Health Service, Health Resources Administration (HRA76-1120, 25 3).

Northrop-Clewes, C. A., Paracha, P. I., McLoone, U. J. \& Thurnham, D. I. (1996). Impact of improved vitamin A status on response to iron supplements in Pakistani infants. American Joumal of Clinical Nutrition 64, 694 699. 
Olson, J. A. (1984). Serum levels of vitamin A and carotenoids as reflectors of nutritional status. Journal of the National Cancer Institute 73, 1439-1444.

Pilch, S. M. (editor) (1985). Guidelines for interpretative criteria. In Assessment of the Vitamin A Nutritional Status of the U.S. Population Based on Data Collected in the Health and Nutrition Examination Surveys, pp. 17-23. Bethesda: FASEB.

Scott, K. J., Thurnham, D. I., Hart, D. J., Bingham, S. A. \& Day, K. (1996). The correlation between the intake of lutein, lycopene and $\beta$-carotene from vegetables and fruits, and blood plasma concentrations in a group of women aged 50-65 years in the UK. British Journal of Nutrition 75, 409-418.

Solomons, N. W. \& Bulux, J. (1993). Plant sources of provitamin A and human nutriture. Nutrition Reviews 51, 199-204.

Sommer, A., Tarwotjo, I., Djunaedi, E., West, K. P., Loeden, A. A. \& Tilden, R. (1986). Impact of vitamin A supplementation on childhood mortality. Lancet i, 1169-1173.

Thurnham, D. I. \& Flora, P. S. (1988a). Stability of individual carotenoids, retinol, and tocopherol in stored plasma (letter). Clinical Chemistry 34, 1947.

Thurnham, D. I. \& Flora, P. S. (1988b). Do higher vitamin A requirements in men explain the difference between the sexes in plasma provitamin A carotenoids and retinol? Proceedings of the Nutrition Society 47, $181 \mathrm{~A}$.

Thurnham, D. I., Munoz, N., Lu, J.-B., Wahrendorf, J., Zheng, S.-F., Hambidge, K. M. \& Crespi, M. (1988a). Nutritional and haematological status of Chinese farmers: the influence of 13.5 months treatment with riboflavin, retinol and zinc. European Journal of Clinical Nutrition 42, 647-660.

Thurnham, D. I., Smith, E. \& Flora, P. S. $(1988 b)$. Concurrent liquid-chromatographic assay of retinol, $\alpha$ tocopherol, $\beta$-carotene, $\alpha$-carotene, lycopene and $\beta$-cryptoxanthin in plasma with tocopherol acetate as internal standard. Clinical Chemistry 34, 377-381.

Thurnham, D. I., Williams, N. R., Evans, A. E., Cambou, J. P. \& Howard, A. N. (1994). Plasma antioxidant nutrients in Belfast and Toulouse. Proceedings of the Nutrition Society 53, 261A.

Willett, W. C., Stampfer, M. J., Underwood, B. A., Taylor, J. O. \& Hennekens, C. H. (1983). Vitamins A, E and carotene: effects of supplementation on their plasma levels. American Journal of Clinical Nutrition 38, 559566.

Zeng, S., Furr, H. C. \& Olson, J. A. (1992). Metabolism of carotenoid analogues in humans. American Journal of Clinical Nutrition 56, 433-439. 